\title{
O não dito ou além do que é dito diretamente: processos sensoriais e afetivos na recepção do espetáculo no método BPI
}

TURTELLI, Larissa . $^{1}$

RODRIGUES, Graziela, E.F. ${ }^{2}$

Como artista deve-se mover o público. Comunicação! É disso que se trata. Um humor, uma impressão, uma idéia,

do âmago do ser para o âmago do ser. Comunicação a partir de uma fonte que está constantemente crescendo, mudando, evotuindo.

Pauline Koner $^{3}$

Resumo

O artigo procura explicitar aspectos dos processos de recepção do espetáculo no método BPI, levando em consideração a perspectiva sistêmica de abordagem do movimento adotada pelo método. São levantados tópicos referentes às memórias, sensações, emoções e micro-movimentos mobilizados na percepção do movimento do outro. São destacadas a abertura consciente das emoções e a postura pró-ativa do intérprete no método BPI em relação a estabelecer um contato afetivo com o espectador. Palavras-chave: Bailarino-Pesquisador-Intérprete (BPI); Recepção; Dança.

\section{Abstract}

The article aims to make explicit aspects of the spectacle's reception at BPI method, taking into account the systemic approach to address the movement adopted by the method. Topics are raised concerning the memories, feelings, emotions and micro-movements mobilized in the perception of another person's movement. Are highlighted the conscious opening of the emotions and the proactive attitude of the performer in the BPI method for establishing an emotional contact with the viewer.

Keywords: Dance-Research-Performer (BPI); Reception; Dance.

1.

Artista e pesquisadora da Dança. Doutora em Artes. Professora Doutora da Universidade Estadual de Campinas UNICAMP, Programa de Pós-Graduação em Artes da Cena (l.turtelli@iar.unicamp.br).

Artista e pesquisadora da Dança. Criadora do método Bailarino- PesquisadorIntérprete (BPI). Psicóloga. Doutora em Artes. Professora MA III $\mathrm{H}$ da Universidade Estadual de Campinas UNICAMP, Programa de PósGraduação em Artes da Cena (graziela@iar.unicamp.br).

3. Koner (1993, p.01) [tradução nossa]. 
O tipo de comunicação que ocorre nos espetáculos criados a partir do método BPI (Bailarino-Pesquisador-Intérprete) ${ }^{4}$ é predominantemente sem palavras. Apesar de muitas vezes haver falas, existe todo um conteúdo transmitido pelos movimentos e, mesmo durante as falas, o corpo nem sempre transmite o mesmo conteúdo dito oralmente.

Os espectadores apreendem o que o corpo da personagem expressa e, esta, o que é manifesto pelos corpos destes. Há da parte do intérprete uma postura ativa nos dois sentidos, no de fazer questão que o público perceba o que a personagem em seu corpo está sentindo e no de fazer questão de perceber o que o público está sentindo.

A postura dos espectadores pode ser variada quanto a estar ou não ativa para esta comunicação. No entanto, apenas o fato de estarem olhando para a movimentação da personagem já faz com que sejam estimuladas sensações em seus próprios corpos, pois o modo de apreensão do movimento do outro é através das próprias referências corporais.

A apreensão do meio externo baseia-se nas alterações corporais e memórias despertadas na interação com o meio: "as imagens que cada um de nós vê em sua mente não são cópias do objeto específico, mas imagens das interações entre cada um de nós e um objeto que mobilizou nosso organismo" (DAMÁSIO, 2000, p.406). O outro só existe para nós na medida em que o criamos em nós, de forma que cada um fará de uma mesma pessoa uma imagem diferente.

A mobilização do próprio corpo é intensificada na relação com outros corpos humanos, pois usamos a própria imagem corporal para monitorar tanto o nosso corpo quanto para codificar a posição, tamanho e movimento dos corpos dos outros (REED; FARAH, 1995).

Logo, o próprio movimento corporal e o movimento corporal do outro não são processados independentemente, quando uma pessoa está movendo uma parte do seu corpo, ela tende a atentar mais a essa mesma parte do corpo de outras pessoas. Por outro lado, quando uma pessoa vê outra se movendo, tem esses mesmos movimentos evocados em seu próprio corpo. "A apresentação visual do movimento de outra pessoa evoca representação similar desse movimento em nosso corpo" (SCHILDER, 1999, p.34).

Assim, a percepção dos movimentos do corpo em cena acarreta em micro-movimentos e sensações nos corpos dos espectadores. Não só o movimento é despertado, todos os sentidos do corpo participam dessa interação.

Nossa impressão sensorial do corpo do outro e nosso interesse emocional pelas diversas partes do corpo, estão intimamente ligados às nossas atitudes emocionais para com o nosso próprio corpo, as quais não podem ser separadas da experiência sensorial.
4.

Método de pesquisa e criação em dança criado por Graziela Rodrigues (Rodrigues, 1997, 2003). 
Os processos afetivos balizam a nossa percepção (SCHILDER, 1999, P.250).

A memória também é despertada nessa interação corpo a corpo entre bailarinos e espectadores: "[a] memória corporal provocada pela dança através das mudanças de estabilidade, de equilíbrio e tonicidade, reporta-nos à nossa história pessoal inscrita em nosso corpo e que o espectador sente sem parar" (PAVIS, 2007, p.283).

Fenômeno semelhante a esse pode ocorrer em outras modalidades de arte, trata-se de uma memória que não é despertada de maneira voluntária, a "imagem mnêmica se constitui de lembranças que surgem espontaneamente, sem a vontade e o controle do sujeito [...] o contrário de um processo consciente de rememoração" (DESGRANGES, 2008, p.17).

Assim, é através das memórias, sensações, emoções e impulsos para o movimento que percorrem nosso corpo que processamos o movimento do outro no instante efêmero no qual ocorre. Nesse sentido a dança, por ser uma arte do movimento, tende a estabelecer um tipo de comunicação que faz com que sejam despertadas nos espectadores memórias de suas próprias experiências que em algum ponto possuem relação com o movimento do bailarino. A afetividade ligada a estas memórias irá direcionar a percepção dos espectadores.

Ao assistir a um espetáculo de dança, a pessoa não está vendo só o que o corpo do bailarino está literalmente fazendo, está sentindo o que este corpo está evocando, a interação entre corpos nos permite irmos para dentro da dança, sentirmonos participantes e não apenas observadores (HODES, 1995; STINSON, 1995).

Dessa maneira, o movimento em si, sem uma elaboração quanto ao seu conteúdo, já tem potencial para causar as mais diversas sensações nos espectadores. Com isso, existem criadores na dança que optam por pesquisar apenas as formas e dinâmicas dos movimentos, sem darem atenção ao aspecto da comunicação. Nos seus espetáculos não há uma elaboração quanto ao que será dito através da dança. Estes coreógrafos deixam a cargo do espectador fazer algum sentido do que estão vendo. Neste caso freqüentemente as criações coreográficas partem, por exemplo, de pesquisas de movimento a partir dos usos do espaço, tempo, peso, e de tipos de movimentos específicos, como quedas, desequilíbrios, choques, entre outros.

Existem gradações entre esses dois pólos, isto é, o foco da coreografia no aspecto da comunicação de determinados conteúdos ou na pesquisa apenas das formas e dinâmicas dos movimentos.

O exemplo mais conhecido de criador que se mantém no pólo da pesquisa das dinâmicas dos movimentos é o coreógrafo norte 
americano Merce Cunningham. As coreografias de Cunningham originam-se de pesquisas de movimento "partindo de resolução de problemas mecânicos, tais como passagens de uma posição para outra, impulsionar o corpo nas elevações, mover-se mais rápido etc." (AZEVEDO, 2004, p.80). Nessas coreografias cabe ao público "a função de selecionar, recortar, organizar e montar o seu próprio espetáculo" (ibid., p.80). No trabalho de Cunningham o movimento é claramente separado "da pessoa do dançarino, do meio no qual ele evolui, do público" (GARAUDY, 1980, p.154).

Na dança criada através do método BPI aborda-se o movimento como um sistema formado da interação de diversos fatores, como as sensações, emoções, imagens, percepções, memórias pessoais e culturais, características físicas da pessoa e pensamentos. Em sendo um sistema, o movimento não é uma somatória, e desse modo não é um resultado estanque posterior à integração destes fatores, ele os traz em si o tempo todo, expondo-os no seu dinamismo. Busca-se considerar os aspectos fisiológicos, afetivos e sócio-culturais inerentes aos movimentos.

Merleau-Ponty (1994, p.210) afirma que o corpo deve ser considerado como "um nó de significações vivas e não a lei de um certo número de termos co-variantes". Esse "nó de significações" modifica-se com nossas experiências:

Por vezes forma-se um novo nó de significações: nossos movimentos antigos integram-se a uma nova entidade motora, os primeiros dados da visão a uma nova entidade sensorial, repentinamente nossos poderes naturais vão ao encontro de uma significação mais rica [...] cujo advento reorganiza subitamente nosso equilíbrio (ibid., p.212).

O indivíduo é uma totalidade, que não pode ser dividida em fatores intelectuais, sociais e motores, pois estes estão todos interligados: "[a] correlação entre os estímulos visceral, psíquico e periférico, a resposta muscular fundamental, envolve o todo de um homem. O corpo inteiro, animado como é pela memória muscular, torna-se um instrumento sensitivo que responde com sabedoria" (VIANNA, 1990, p.91).

Abordar de forma integrada e vivencial a gama de fatores intrínsecos ao movimento só é possível considerando-se a individualidade dos movimentos de cada bailarino, focando a pesquisa de movimentos na originalidade de cada corpo.

Na coreografia criada através do BPI, os movimentos provêm de um exercício constante de integração de sensações, emoções, imagens, percepções e memórias. Procura-se desenvolver um trabalho que agregue de forma consciente esses vários fatores constituintes do movimento e que tenha intencionalidade quanto ao que será expresso através destes. Existe um conteúdo a ser 
transmitido ao espectador e uma intenção de tocar a sensibilidade das pessoas do público.

Durante a performance o intérprete, via a personagem, está aberto em suas emoções e ao mesmo tempo em um estado de atenção e porosidade para captar as emoções dos espectadores e reagir a elas. Essa abertura das próprias emoções favorece uma abertura emocional também dos espectadores.

A abertura consciente das próprias emoções está relacionada a não ficarmos presos aos nossos mecanismos de defesa. ${ }^{5}$ Como afirmam Cunha e Crivellari (1996, p.62): "[a] permanência dessas defesas fixadas no tempo interrompe a capacidade individual para o contato, tanto internamente consigo mesmo, quanto externamente com os outros".

O movimento realizado com uma carga emocional possui características diferenciadas daquele realizado sem o envolvimento emocional do intérprete. Existe toda uma situação fisiológica provocada pela vivência de uma emoção que não é possível de ser construída pelo controle voluntário de cada um dos seus constituintes.

Nos movimentos expressivos existem padrões de movimento desencadeados pelo sistema nervoso autônomo que são difíceis de serem reproduzidos voluntariamente, fazem parte desses padrões diversos movimentos intrinsecamente relacionados que ocorrem não apenas na musculatura esquelética, como também nas vísceras, glândulas e sistema nervoso central. Em vista disso existe uma diferença significativa na qualidade dos movimentos desencadeados como conseqüência de uma emoção que está de fato sendo sentida pela pessoa e dos movimentos fruto de uma "representação" de uma emoção.

Esses padrões específicos de reações do corpo que são desencadeados pelas emoções "constituem um todo", que não é alcançado com a simples soma de suas partes. "Quando ocorre um movimento expressivo como a súplica, o desafio ou a tristeza, não se percebem os elementos isolados da tensão muscular, e sim seqüências específicas que constituem um todo" (SCHILDER, 1999, p.230).

Por conseguinte, esses movimentos não podem ser reproduzidos um a um até que se chegue à figura completa, precisam ser desencadeados como um todo em decorrência da vivência de determinada emoção. A qual, essa sim, pode ser desencadeada de diferentes maneiras.

Essa situação corporal única configurada pelo movimento expressivo traz uma qualidade para a performance na qual o movimento ganha outra densidade, o corpo expande-se, pois contempla o seu conteúdo interno.

Essa qualidade expressiva é identificada sensivelmente pelo espectador, propicia que sejam despertadas nele emoções relacio-
5.

Segundo Pruzinsky (1990) os mecanismos de defesa são formas que aprendemos para lidarmos com o mundo, que incluem estratégias cognitivas, emocionais e corporais. Estes mecanismos são empregados repetidamente, internalizados e se tornam inconscientes. Muito depois de a necessidade de um enfrentamento de determinada maneira ter passado, nós continuamos a empregar os mesmos mecanismos de defesa. 
nadas às que estão sendo expostas, emoções estas relacionadas às memórias de cada um. Pode-se afirmar que existe um "contágio psíquico" quando entramos em contato com outra pessoa sentindo determinada emoção "[a]s emoções que encontram sua expressão no modelo postural do corpo, no tônus, na motilidade, no sistema vasovegetativo, necessariamente são transmitidas de uma pessoa para outra" (SCHILDER, 1999. p.310-311).

Assim, através do movimento expressivo é possível chegar a estabelecer uma qualidade de contato entre intérprete e público que favorece ao espectador "uma profunda penetração nos mais íntimos recessos da vida e da existência humana que, se trazidos à tona, poderiam ajudá-lo a recuperar algumas de suas qualidades essenciais perdidas" (LABAN, 1978, p.28).

Ter um cuidado quanto às relações estabelecidas com o público e uma postura ativa quanto a envolver o público nas situações propostas pelo espetáculo não é o mesmo que querer agradar o público. O objetivo é promover o contato, a abertura de um canal sensível para que possa ocorrer a comunicação.

Via de regra nos espetáculos no método BPI existe uma alternância entre causar encantamento e estranhamento nos espectadores. Se o encantamento tem a ver com empatia, identificação, o estranhamento está relacionado a um incômodo, a tirar as pessoas do conhecido, do acomodamento. Em ambos os casos existe uma relação de proximidade emocional. A emoção encurta as distâncias. Schilder (1999, p.312) afirma: "dor, alegria, destruição, mutilação, morte são a preocupação daqueles que estão próximos de nós, mas um fluxo mágico conecta os mais próximos com os mais afastados, e passa até ao animal, à planta, e ao mundo inanimado".

Seja pela empatia ou pela rejeição, existe constantemente em cena uma intenção de envolver o público, manter instaurado o espaço do fluxo personagem-público-personagem, um espaço único que rompe com os limites do espaço cênico.

Os conteúdos vividos no corpo da personagem irão atingir os espectadores em diferentes níveis. Nas palavras de Rodrigues (1997, p.24) "cada pessoa vivencia o trabalho no nível em que está preparado para recebê-lo". Algumas apreensões vêm antes de um entendimento racional e ativam toda uma rede de sensações, memórias e emoções no corpo do espectador. A consciência da extensão desta rede colocada em movimento na pessoa depende do nível de contato interno de cada espectador.

O espetáculo no método BPI exige uma auto-entrega do intérprete para permitir que seu corpo em movimento seja veículo de emoções, sensações e imagens que estão além da sua individualidade. O espetáculo não acontece de fato se apenas reproduzido através da repetição dos movimentos das coreografias e das ações expressivas. 
Essas emoções que emergem do intérprete através da personagem, são elaboradas junto à direção durante o processo criativo para que o intérprete possa conduzi-las de forma consciente ao longo do roteiro e tenha o conhecimento das ligações que as emoções da personagem fazem com suas experiências pessoais.

Na atuação do intérprete no espetáculo no BPI: "há uma dádiva do sujeito, ele está inteiro em cada fragmento de cena, o conteúdo do espetáculo faz parte dele. No entrelaçamento sujeito-personagem o bailarino não interpreta, mas vive no seu corpo a vida dimensionada pelo espetáculo, sem restrições". (RODRIGUES, 1997, p.19).

A personagem toma a frente e traz consigo todo um campo social, a partir do seu eixo de referência não há limites para as conexões que ela pode fazer.

\begin{abstract}
Neste trabalho a dança é concebida no sentido interno antes de ganhar representação, o corpo todo dança de dentro para fora, entra em relação, recebe dados vindos do exterior, que são identificados pelo canal emocional, elaborando-os e transformando-os em movimento, em espaço-paisagens, em cheiros, odores, sabores e tantos outros que forem precisos para ganhar força, única para cada pessoa. São os sentidos ganhando forma com força motriz e preenchendo os espaços, projetados pelo intérprete. (RODRIGUES, 2003, p.137)
\end{abstract}

As personagens nos espetáculos do método BPI trazem uma força para superar as adversidades e lutar pela vida, a qual se conecta à força de resistência presente em muitas pessoas que vivem nas margens da sociedade, pessoas encontradas nas pesquisas de campo das manifestações culturais populares brasileiras: "[e]sta é uma força que supera o peso da opressão imposta ao corpo e procede de algum tipo de esperança que indica ao ser humano que vale a pena lutar pela vida". (RODRIGUES, 1997, p.128)

Gauthier (1999, p.27) destaca essa presença, desses corpos das margens, no corpo do intérprete trabalhado no método BPI: "é a constituição do povo brasileiro, notadamente através da escravidão e do confronto/troca entre culturas, tais como ela foi internalizada e silenciada dentro do corpo, que é interrogada na experiência singular de pesquisa de Graziela Rodrigues”. O autor sintetiza o processo do BPI vivido pela primeira vez no corpo de sua criadora, Graziela Rodrigues, como:

Trabalho de empatia com as mulheres reais, que sofrem e resistem, descoberta dos corpos de mulheres conservados vivos nas culturas de resistência, colocação em crise do seu próprio corpo construído pela academia, expressão de um modelo espiritual de corpo popular, entre outros possíveis (virtuais)... (ibid., p.28) 
Por outro lado, as manifestações culturais populares perdem sua força, deixando de estar vivas e tornando-se reprodução, se não forem nutridas pelos seus participantes através de seu movimento interior - seus afetos, memórias, imagens internas, devoções e esperanças - o qual se conecta aos fundamentos da manifestação em questão. Quando esta conexão interna é perdida:

A dança deixa de ser compartilhada para ser apresentada. Nestes casos o fator externo passa a ser mais importante, a festividade sai de seu contexto e de seu lugar [...] Vimos vários grupos com o figurino impecável, a coreografia certinha, e todos sabedores da história de sua origem e desenvolvimento. Porém seus corpos não tinham nada a dizer, só a representar, como se as imagens e as lembranças não mais circulassem pelo corpo (RODRIGUES, 1997, p.66).

De maneira semelhante, o espetáculo no BPI precisa ser constantemente nutrido para manter sua vitalidade, através da abertura da sensibilidade do intérprete para o mundo e da dinamização das suas paisagens internas, ligadas aos afetos, memórias e sensações.

Esta força dos corpos das culturas de resistência de alguma forma circula no espetáculo no método BPI através das conexões afetivas instauradas a partir do campo emocional da personagem e é compartilhada com o público.

A personagem faz surgir um espaço em comum com o público, local tomado pela manifestação artística. O que acontece neste "espaço mágico" supera as individualidades. De maneira semelhante ao que acontece em algumas manifestações culturais populares, quando estas apresentam um caráter de resistência cultural, existe um sentido para a realização da dança que vai além do intérprete e de cada pessoa que assiste ao espetáculo, algo que de alguma forma os irmana, mesmo na diferença, e os transcende, conectando-os a uma realidade mais ampla. 
AZEVEDO, S.M. O papel do corpo no corpo do ator. São Paulo: Perspectiva, 2004. (Coleção Estudos; 184).

CUNHA, M.G.G.; CRIVELLARI, H. Caminhando com a psicoterapia integrativa. Belo Horizonte: Cultura (impressão gráfica), 1996.

DAMÁSIO, A. O mistério da consciência: do corpo e das emoções ao conhecimento de si. São Paulo: Companhia das Letras, 2000.

DESGRANGES, Flávio. Teatralidade tátil: alterações no ato do espectador. Sala Preta, Programa de Pós-Graduação em Artes Cênicas da Escola de Comunicações e Artes da Universidade de São Paulo, São Paulo, n.08, 11-19, 2008.

GARAUDY, R. Dançar a vida. Rio de Janeiro: Nova Fronteira, 1980.

GAUTHIER, J. O que é pesquisar - entre Deleuze-Guatarri e o candomblé, pensando mito, ciência, arte e culturas de resistência. Educação \& Sociedade. v.20, nº69, p.13-33, 1999.

HODES, S. Dance and essence: reflections on morality and education. Arts education policy review, [S.1.], v.97, n.2, 2-13, 1995.

KONER, P. Elements of performance: a guide for performers in dance, theatre and opera. Amsterdam: Harwood Academic Publischers, 1993.

LABAN, R. Dominio do movimento. São Paulo: Summus, 1978.

MERLEAU-PONTY, M. Fenomenologia da percepção. São Paulo: Martins Fontes, 1994. (Coleção Tópicos).

PAVIS, Patrice. Dicionário de Teatro. São Paulo: Perspectiva, 2007. (Tradução J. Guinsburg e Maria Lúcia Pereira. za edição).

PRUZINSKY, T. Somatopsychic approaches to psychotherapy and personal growth. In: CASH, T.F.; PRUZINSKY, T. (Eds.). Body images: development, deviance, and change. New York: The Guilford Press, 1990. p.296-315.

REED, C.L.; FARAH, M.J. The psychological reality of the body schema: a test with normal participants. J. exp. psychol. hum. percept. perform., [S.1.], v.21, n.2, 334-43, 1995.

RODRIGUES, G. Bailarino-Pesquisador-Intérprete: processo de formação. Rio de Janeiro: Funarte, 1997.

RODRIGUES, G.E.F. O Método BPI (Bailarino-PesquisadorIntérprete) e o desenvolvimento da imagem corporal: reflexões que consideram o discurso de bailarinas que vivenciaram um processo criativo baseado neste método. 2003. 171p. Tese (Doutorado em Artes) - Instituto de Artes, Universidade Estadual de Campinas, Campinas, 2003. 
SCHILDER, P. A Imagem do Corpo: as energias construtivas da psique. São Paulo: Martins Fontes, 1999.

STINSON, S. W. Body of Knowledge. Educational-Theory, University of Illinois, [S.l.], v.45, n.1, 43-54, 1995.

VIANNA, K. A dança. São Paulo: Siciliano, 1990. 